\title{
ON THE IMPORTANCE OF AQUEOUS VAPOR IN WARMING AND VENTILATING DWELLING-HOUSES,
}

\author{
By Charlegs M. Wetherill, Ph. D. M. D. \\ Professor of Chemistry in the Lebigh University.
}

THE irnportance of the vapor of water in the atmosphere of our dwellings during the winter season, is not denied by any one; but the proper means for securing this condition is neglected, even by those who acknowledge its importanee, and in the various appliances for hydration in the construction of hot air furnaces the means adopted are entirely inadequate.

The writer has had his attention forcibly directed to this subject by a series of experiments and analyses made in Washington, in 1866, upon warming and ventilating the Capitol (House of Reps., 39th Congress, 1st Session, Ex. Doc. No. 100), and now again in his own dwelling, and also in the new university building, Packer Hall, which is warmed by an abnormally dry air, made so by pass. ing over steam coils, as in the capitol.

He has thought that a few remarks would not be out of place in this connection, and he would feel amply repaid if any of our practical men, profiting by the suggestions, would supply the deficiencies complained of, and advance their fortunes by the invention of a hot air furnace constructed upon scientific principles.

This problem has never been solved practically, and yet it admits of a solution.

A great difficulty meets us in the outset, viz: an inertia to be overcome in the public mind, as well as in the opinions of practical men, with respect to the requisites of a more perfect system of warming and ventilation. Thus a class of inventors direct their attention to the construction of the stove to ensure economy of fuel and rapidity of warming the air, and another class discuss the merits of a downward or upward ventilation, while all (even those who admit the necessity of it), neglect the consideration of the best means of effecting the hydration of the air, at least in dwellinghouses, and of the actual amount of water necessary for the purpose.

As a result of the experiments at $W$ ashington, after much money had been spent for the investigation, and after it had been proved conclusively by the experiments that the warmth and ventilation

Vox. LVII.-ThIRD SBRTHs.-No. 3.-MARCH, 1869 
were abundant (even excessive), and that the sole cause of discom. fort arose from too low a relative humidity in the air, Congress could or would only appoint a fresh committee to inquire into the means of procuring a more efficient ventilation for the Capitol!

In the furnaces which admit the necessity of water, a small panful is afforded, without any further consideration of its efficiency, when the dried up feelings and warped furniture of the inmates of the house are protesting constantly as to its inadequacy.

We use the term "relative humidity," to designate the percentage of water which air of a given temperature holds in solution as vapor. Thus, when air of any given temperature contains all of the moisture, which it is able to hold as vapor, we say its relative humidity is 100 ; if it contains half as much, its relative humidity is 50; relative humidity 10 , indicates that the air has 10 per cent. of the vapor of water, which it is able to hold at that temperature.

It is a property of air that the quantity of water which it may dissolve to saturation, increases with the temperature of the air. Hence, air which is saturated with water at $70^{\circ}(i . e$. has a relative humidity of 100 ), may still have a relative humidity of $100^{\circ}$ (i.e. be still saturated with water), when cooled down to $32^{\circ}$ but does not contain so many grains of water per cubic foot as it did, a portion having been precipitated or condensed as drops of water by the effect of the cooling. Conversely, air having a relative humidity at $32^{\circ}$ of 100 , has its relative humidity reduced to 50 by being raised to a temperature of about $50^{\circ} \mathrm{Fah}$.; or to 25 , if it be heated to about $72^{\circ}$.

When the air is moist, we say that it has a high relative bumidity; and when its relative humidity is low, we say that the air is dry.

What is the effect of these two conditions upon the human body? When the air is saturated with moisture the evaporation from the skin and lungs is arrested, and those interior movements of the bodily fluids necessary to health are restricted. The body is in the condition obtained by the Russian bath, but without its elevated temperature; is in an unnatural condition. The amount of animal heat removed by the evaporation of the corporeal moisture is no longer withdrawn. Even the beneficial effects of the Russian bath are wanting, for the shock to the nervous system is absent.

When the body is in air of too low a relative humidity, the opposite conditions are present. An abnormally large amount of heat is abstracted by the evaporation; the motion of the corporeal fluids 
is excessive; the necessary moisture is removed from the lungs and skin, we feel parched and dry; fevers and susceptibility to cold, together with other human ills, are manifested.

Who has not noticed the great access of disease and of lesser bodily disturbance which a dry heated term of our summers is sure to bring? These evils may all be observed in our furnace heated winter dwellings, and are making their impression particularly upon the rising generation of our cities. Dr, John Bell has said that we, "of the middle states, are nearly in the situation of those who should spend thẹir summer in Egypt and their winter in Russia." Desor attributes the restless nervousness of Americans to the dry. ness of our climate.

We can overcome these difficulties, at least in the winter, by at. tending to the relative humidity of our dwellings, and we may constantly test their degree of humidity by the simple hygrometer of Edson or of Mason.

The problem to be solved falls into two parts:--

1st. What is the relative humidity for an agreeable temperature most conducive to health?

2. How may we maintain that humidity by a hot air furnace.

If we determine the amount of moisture needed in the air for health, we can ascertain very readily the quantity of water in the cold air, and consequently how much we must add to it to give it when warmed, the healthful relative humidity. It will be the duty then of the furnace (supported by a proper construction of the building for ventilation), to give this water.

The problem is a very difficult one for large halls filled with an audience, but for private dwellings is much simpler.

1. Experiments upon the first bead are wanting.

We will not go astray, though, if we assume that the Creator has placed us to live in an external atmosphere of the proper relative humidity, and that since he has given us, through our reason, the power to combat the cold of winter, we may use the same faculty to draw proper conclusions as to atmospheric moisture.

The relative humidity of the external air varies from 100 to 12 , and lower. It is greater in winter than in summer, although in winter there is less water in the air on account of the cold having condensed the moisture. The mean relative humidity of the year will give us that quality of air best suited to our nature, and that which we must imitate in our plans for artificial warming and ventilation. 
The mean relative humidity of Washington for the years 1856 $58-59$, was $68 \cdot 15$.

That for Philadelphia from twelve years observation was 68.5. Müller gives the annual mean relative humidity of Halle, Germany, at 75. Roscoe states that the experience of heating and ventilating the House of Lords, demonstrated the most agreeable relative humidity to be not less than 55 , nor more than 82 , of which the mean is 68.5. My own observations of the air of the Mammoth Cave of Kentucky, showed a relative humidity of 87.6 and a temperature of $58^{\circ} ;$ an agreeable temperature and humidity for exercise.

These considerations lead us to adopt for the relative humidity of our winter dwellings the standard which nature furnishes us; it should range between 50 and 75 , of which the mean is 67.5 . It should be, as I have given it, slightly lower than the annual mean, since the relative humidity is a little higher in winter than in summer. The proper degree of kumidity in our warmed rooms renders a lower temperature agreeable; the moisture in the air acts like a blanket to retain the heat of the body.

2. In order to maintain the relative humidity of the air of apartments at a given point, say only 50 for a temperature of $70^{\circ} \mathrm{Fah}$., the temperature of the external atmosphere being at $32^{\circ} \mathrm{Fah}$, and nearly saturated with moisture, we have to make calculations which will give varied results, according to the construction of the house. We must consider how much warm air per minute enters it from the furnace, and how much from the external atmosphere by the windows and doors, the sum of these leave it per minute, and constitute the ventilation. Also what are the number of its inmates, and how many lights are burned; although this is of minor im. portance in private dwellings, where the ventilation is generally in excess.

In a sleeping room in Washington, heated by a fire in an anthracite grate, and occupied by two adults and two children, the relative humidity in the morning before any doors were opened, was 46 , the temperature of the room being $68 \cdot 4 \mathrm{Fah}$. The carbonic acid was only double that existing in the external air, demonstrating a very efficient ventilation effected by the chimney.

The following calculations must be regarded as giving only general results to direct attention to the subject, and to form a basis upon which to experiment for the attainment of a more perfect furnace.

A cubic foot of air at $32^{\circ} \mathrm{Fah}$, when saturated contains $2 \cdot 126$ 
grains of water. Let us suppose that it is nearly saturated, and contains 2 grains. If it be raised in temperature to $70^{\circ}$, its capacity for moisture is raised to nearly 8 grains, and as no water has been added, it is no longer nearly saturated, but is very dry. Let us see how much water it contains. Air expands $\frac{1}{9}$ of its volume for every degree above $32^{\circ}$ Fah.; 492 cubic feet at $32^{\circ}$ would become 530 cubic feet at $70^{\circ}$; hence, 1 would become 1.077 cubic feet. These would contain the two grains of water; hence 1 cubic foot would contain only 1.85 grains of water; its relative humidity has been reduced by the warming from nearly 100 to 23.11.

If we take the minimum relative humidity (viz. 50), that can be afforded for health, this cubic foot of air should contain 4 grains instead of 1.85 of water; there is therefore a deficiency of 2.15 grains for every cubic foot of air of the apartment. In a room of $15 \times 20 \times 12$ feet, containing 3,600 cubic feet, this deficiency would equal 7,740 grains of water, or more than a pint (which equals 7291.11 grains), and in a house of eight times the capacity of the above room, the deficiency would be 61,920 grains, or a gallon plus half a pint.

Every time the air of the house is renewed, a gallon of water must be added to give its minimum relative humidity of 50 .

The inmates of a room add water to it from their skin and lungs which, according to Hood, amounts to 12 grains per minute, and according to Seguin 18 grains. But carbonic acid is also added, and this must be removed by the ventilation. Hood estimates the ventilation for one inmate at $\frac{1}{4}$ cubic foot per minute for the car. bonic acid, and $3 \frac{1}{2}$ for the bodily moisture, say about 4 cubic feet per minute. If these 4 cubic feet per minute were not removed, in every hour, only 720 grains of water would have been added to the air from the person of the inmate of the room, leaving still 7,020 of water to be supplied to maintain the relative humidity at 50 .

The non-removal of the products of respiration for one person in a room of 3,600 cubic leet capacity for an hour, upon the supposition that such person exhales 0.7 cubic feet of carbonic acid in that time, would give to the air 6 volumes per 10,000 of that deleterious gas; or two volumes more than the quantity naturally present in the air, which is four volumes. It would require 103 persons to give to the above room by the evolution of their bodily moisture the proper degree of relative humidity, and they would bring the proportion of carbonic acid up to 21. 
(upon the supposition of no ventilation), a quantity entirely too high for health. It follows from this, that it would be impossible to rely upon the respiration and perspiration as a means of supplying a healthful moisture to the air, to say nothing of the disgusting fact of breathing again air thus vitiated.

\section{The absolute amount of water to be supplied.}

If we knew how often the air of a house, of the capacity cited, were changed we could easily calculate the water necessary to be added to maintain a relative humidity of 50 .

Thus, if in our example it were changed every hour, a gallon and a pint of water must be added to it every hour.

If all of the fresh air came to the room through the register of the furnace, the problem would be less complex, for the proper amount of moisture could then be added at once in the hot air chamber: but a large portion of the air comes from the external atmosphere proceeding from the opening of doors, or drawn into the room through the cracks of the doors and windows. If there be a system of ventilating flues, the renewal of air may be regulated to a certain extent, but if there be open fire-places or fires burning in grates, the ventilation is frequently excessive, and more water of bydration is required per hour. In either case, a large portion of its fresh air enters the room by the cracks of the doors and windows. This obliges the furnace air to be hydrated to a greater extent, in order to maintain a relative humidity of 50 in the room. We must avoid the mishap of having such an excess of water that it is deposited in the liquid condition, especially when the heat is turned off from a larger to a smaller number of registers. Hence, to be perfect, an apparatus for hydration should admit of regulation. With respect to the rate of the renewal of the air, it has been found necessary in the halls of Congress to change it every eight minutes, $i$. e. seven and a half times each hour. This rate would not be required for an ordinary dwelling-house, nor could it be effected without powerful means; it would need the evaporation of nearly eight gallons of water per hour.

General Morin performed a series of experiments upon the ventilating effects of chimneys, and the crevices of windows and doors, upon an office in the Conservatoire des Arts et Metiers. (Expériences sur les effects de ventilation produits par les cheminées d'ap. partment Comptes Rendus LVI. p. 16, 1863.) The room could 
be beated at will by an open fire, or by the register of a hot air furnace. He found that the chimney without fire ventilated the room abundantly, He measured the air entering the room, and that evacuated, by determining its velocity by means of a delicate wind wheel, and found that when the external air had a temperature between $35^{\circ}$ and $50^{\circ} \mathrm{Fah}$, and the interior temperature ranged from $64^{\circ}$ to $71^{\circ}$, the chimney withdrew from the room, every minute, 235 cubic feet of air (more correctly 235 $\frac{1}{2}$ ), of which 90.30 entered from the hot air furnace and 144.77 through the crevices of the windows and doors. Or about three-fifths of the air entered by the crevices and was warmed by the remaining two-fifths of air furnished by the furnace. The quantity of fresh air thus added every minute, would be contained in a cube, whose edge is a little more than six feet.

Applying these data to our hypothetical house, the air would be renewed every quarter of an hour, and would require four gallons and two pints of water to be furnished to the house every hour. Such ventilation is excessive; one-half, perhaps even one-quarter would probably be sufficient for an ordinary dwelling, which would require the addition of two gallons of water (or of one gallon), per hour. It would depend upon the ratio existing between the fresh air furnished by the registers, and that admitted to the house through the crevices, how much of this water could be added by evaporation in the hot air chamber of the furnace.

It is apparent from these considerations, that the hot air of the furnace must contain water almost to saturation in order to effect a healthful humidity, and that the small pan of water in furnaces is entirely inadequate to the purpose. The following experiment was performed in the investigation of the ventilation of the Capitol. An iron tank, containing sixty square feet of water surface, and warmed to $172^{\circ} \mathrm{Fah}$. by steam pipes, was placed in the main hot air duct of the House of Representatives. A volume of hot air of the capacity of the House of Representatives passed over this tank every eight minutes, causing the evaporation of not quite fifteen gallons of water per hour ; the increase of moisture in the air due to the tank was not more than half a grain per cubic foot of air. With a less active ventilation, the amount of water per cubic foot would have been somewhat greater; but it follows from the experiment that the rapid passage of air over a heated surface of water is not sufficient for it's hydration. It is necessary to furnish the water more rapidly as by boiling it; I should have liked to have kept the water in this tank in a state of rapid ebullition. 

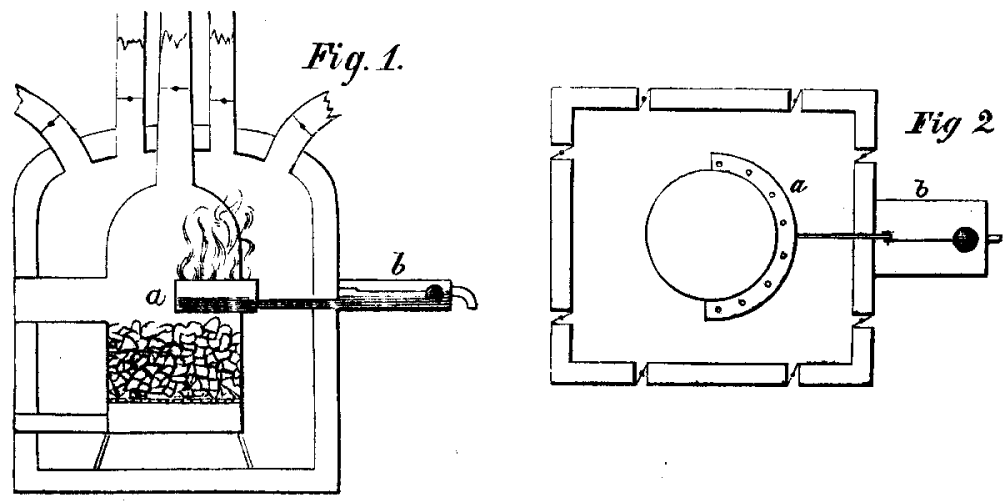

The following suggestions are offered to practical men for an improvement in furnaces.

1. Cease improvements of the stove, making it more complicated and expensive and saving both coal and the trouble of charging it, until a good water supply capable of being regulated is obtained. This would not prevent the supply of moisture to any such com. plex furnaces if they be preferred.

2. Save the coal, as is done, by dampers in the fire flue and register, in the ash-pit and stove-door. Also by attention to the quantity of air passing through the hot air chamber governing it by dampers in the hot air ducts near the stove, and in the cold air ducts; pay. ing also great attention to the air leaving the apartments, and regulating it as much as possible.

3. Seek some method of adding steam by the action of the fire, and in regulated quantities under control, to the hot air chamber. Perhaps the water tromp for obtaining a blast by the fall of water or the atomizer may be made available. Perhaps some means for the evaporation or atomization of water in the apartment may ren. der assistance in maintaining the proper relative humidity.

The admission of steam to the hot air chamber does not rest upon theory only; it has been carried out in practice by Professor Henry at his dwelling in the Smithsonian Institution. "An iron tube connected with the water vessel in the hot air chamber, was inserted through the side of the furnace into the midst of the burning fuel ;" this device kept the water in the vessel in a state of rapid ebulli. tion, raised the relative humidity of his apartments, and a quality 
of "softness and salubrity were imparted not before perceived" in the air.

4. The above sketch is suggested, in which Fig. 1 represents a vertical, and Fig. 2, a horizontal section of a furnace improved for hydration. The supply tank, with ball cock, may be placed inside of the air chamber, providing for an overflow through the wall. The water back should not be in the fuel, and devices should be present to prevent unpleasant results from derangement of the water apparatus:

The water must boil at the rate of a gallon, or more, per hour ac. cording to the ventilation, for a moderate dwelling.

\section{THE NATIONAL WATCH COMPANY.}

By Prof. S. W. Robingon, C. E.

ON passing through the pleasant little city of Elgin, Illinois; a few weeks since, I ventured to sacrifice a few hours of time at that part of my journey, with a view to visiting the National Watch Company's Works, located at that place, to catch a glimpse, if possible, of those wonderful machines that turn out the tiny wheels, which, by their undeviating movements in their allotted spheres, measure off so truthfully the few fleeting moments of human existence. The buildings were reached by about half a mile's walk from the depot. They were originally located at some distance from other buildings and streets, to avoid dust and confusion, but the hundreds of operatives who have come to populate the working rooms of the establishment, and furnish brains to the machines, are building up houses in the vicinity, so that the isolation of the buildings is not so complete as formerly. They consist of a main part, about 40 feet square and three stories high, with which are connected three wings; those toward the east and west being 100 by 28 feet, and two stories high. The south wing, 87 by 28 feet, has one secondary wing, 25 by 35 feet, extending eastward, and the engine room, 30 by 65 feet, on the west side. All are substantial structures, consisting of brick and stone. On entering the janitor's room, and furnishing to one of the proprietors, called for the purpose, sufficient assurance of unobjectionable motives, ready access was granted to the various rooms and departments.

Vol. LVII.-Third Series.-No. 3.-March, 1869. 